\title{
Ecology and Conservation of the Diamond-backed Terrapin
}

\author{
Editors: Willem M. Roosenburg \& Victor S. Kennedy \\ Johns Hopkins University Press, ISBN 978-1-4214-2626-6. Hardback, 368 pp.
}

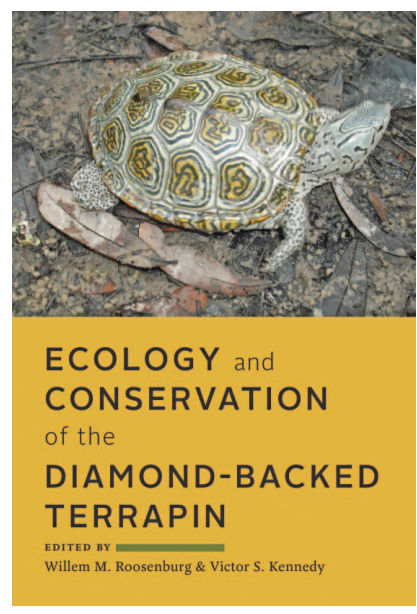

expected a very readable and informative text from this publisher on a fascinating terrapin, and I was not disappointed. In his introduction, Whit Gibbons summarises exactly how the various topics are dealt with. He includes the sentence "The terrapin story offers insight that can be applied to developing effective conservation practices for any overexploited species" and this would particularly apply to other chelonians. We need to be quite clear about nomenclature: whereas some emydid turtles (Pseudemys species) can be referred to as terrapins, in this book 'terrapin' only applies to Malaclemys terrapin.

The book is well structured, with individual chapters by researchers on each topic. Each comprises a combination of the expertise of the individual authors, plus information gleaned from a review of relevant literature, and thus there are many references in the text. There are diverse situations to describe, as the diamond-backed terrapin ranges from the Gulf of Mexico up to Cape Cod, and as well as climatic extremes it also inhabits water of varying salinity. The book begins with descriptions of the various search and capture methods in this terrapin's different habitats. The difficulty in finding this species means observation of secondary clues may be needed, such as the presence of snails showing metacercarial cysts of a trematode whose final host is exclusively the diamond-back. There are details of how to assemble and use the various items of equipment needed for capture, measurement and humane marking, and the experience of the authors even extends to warning readers not to let sticky estuarine mud suck off their shoes.

Moving on to taxonomy, a new 3-tier system of categorising subspecies is suggested to try and address the conflict in nomenclature. There is a wide range of morphological differences in the seven subspecies, but not the expected corresponding genetic variation, with the reasons clearly discussed.

The chapter describing the biology of hatchlings and juveniles, while giving comprehensive information, highlights more than any other topic the need for further research. As with other chelonian species, the cryptic lifestyle of young terrapins means there are still many gaps in our knowledge which need to be filled to inform conservation strategies. For example, the suitability of various soil types for hibernation, and whether hatchlings prefer to head inland after emergence from the nest, need further investigation. This sort of information can be vital when land is earmarked for development and terrapins may be present.

The thermoregulatory ability of the diamond-back is very clearly explained, including enough biochemical details to show exactly how cryoprotectants allow survival at low temperatures that would be lethal to most other chelonians. Similarly, the homeostatic mechanisms that enable the animals to move between areas of differing salinity are well explained, including behavioural strategies as well as physiological aspects down to cellular level.

The section on temperature-dependent sex determination gives a wealth of information gleaned from the literature, and again, has precise details of where further research is needed. This is of particular importance in a world where climate change threatens the sex ratio of animals whose developmental conditions influence the sex of the offspring.

Foraging and habitat selection are considered together, being linked by prey preferences of the different age classes in their varied environments. Sexual dimorphism is another factor in prey choices, with the wider gape of females allowing larger molluscs to be consumed. There are discussions on the terrapin's place in the food web, whereby this top predator can spread seeds of, for example, eelgrass Zostera marina which it can consume incidentally while feeding on epibiota such as barnacles. Again, there are opportunities for further research, one of which is whether terrapins will consume alien species which are competing with local fauna. I was pleased to note that this section comments on the invasive and possibly unethical methods of investigating ingesta, with suggestions for moving on from these traditional studies.

Turning to toxicology, terrapins' reproductive cycles and other hormonal systems are described, with reference to endocrine disrupters. From this point onwards, the book becomes a more depressing read, documenting the population crash which has been caused entirely by mankind. All the usual suspects are mentioned: terrapin overfishing; habitat loss due to development; fatal injury from motor vehicles and motorboats; by-catch in crab pots; 
and so on. On a brighter note, there is plenty of information in the last few chapters on steps being taken to mitigate these serious threats. It is heartening to learn that in spite of being hampered by political and industrial wrangling, the Diamondback Terrapin Working Group (DTWG), established in 1994, has made great strides in achieving protective legislation, and continues to gather support in pressing for more regulations and better enforcement.

If I have to find a criticism of this book, it would only be the fact that there are no colour illustrations apart from the attractive cover photos. However, the images are clear and serve their purpose, and there are other sources of colour photos if an identification guide of the subspecies is required, such as Ernst \& Lovich (2009).

Although each topic has a chapter that stands alone, there are threads running through where the reader is referred to other sections, emphasising the significance of particular issues. The Bermuda mystery, i.e. the question of why it is the only Atlantic island on which diamond-backed terrapins exist in the wild, is a thread that appears in several chapters.
The evidence, or lack of it, is revealed in the sections on field techniques, evolutionary history, palaeontology, molecular ecology and phylogeography, but you'll have to read the book yourself to find out the conclusions.

\section{REFERENCE}

Ernst, C.H. \& Lovich, J.E. (2009). Turtles of the United States and Canada (2nd edn). Johns Hopkins, Baltimore; pp 344361.

\section{CHRISTINE TILLEY}

The British Chelonia Group, PO Box 16216, Tamworth, Staffordshire, B77 9LA, UK

Email: testudo@britishcheloniagroup.org.uk

Received: 22 March 2019 